concerned-I should like to say a few words as to the form of battery employed in this case. One of the great objections to the use of the galvano-cautery in all cases is the difficulty of obtaining an electrical apparatus on which one can depend. For some years I have been frequently in the habit of using the galvano-cautery in small operations about the mouth, nose, and throat, and in cases where some such powerful agent is required, nothing can equal for efficiency and painlessness the use of the white hot wire. But this instrument can never come into general use, as long as we are dependent in some form or other on the bichromate cells. Powerful as the bichromate battery undoubtedly is, the rapidity with which it becomes polarised, the difficulty and expense of always keeping it properly charged, and its liability to fail at the moment when it is most wanted, are drawbacks which to the minds of most men more than com pensate for its advantages. In my own practice I had almost completely abandoned the use of the galvano-cautery, and I was hoping that some other form of cell would be devised which would be more convenient for general and frequent use. Such I believe will prove to be the case with econdary batteries or storage cells. The special form employed in the case I have related was that devised by $\mathrm{Mr}$. Prescott of this city, who kindly lent me three cells for the occasion. These were charged by being placed in the circuit of a dynamo-machine for about half an hour. The manner in which they worked during the operation left nothing to be desired, and at its termination, the intensity of the current was not appreciably diminished. As I have had several opportunities of using them lately in smaller operations about the throat, owing to the kindness of $\mathrm{Mr}$. Prescott, I can speak confidently of their efficiency. The one drawback to them at present is that they do not hold the charge they have received longer than two or three days, at least not in a sufficient degree to employ it for surgical purposes, but I have no doubt that before long they will be improved in this direction. The galvano-cautery will then become more popular, and we shall then hear less of those evil consequences which are generally due to the inconveniences and uncertainties which have hitherto attended its use.

Mr. Prescott informs me that from several experiments made with these cells it has been ascertained that each cell when fully charged yields 4000 ampère minutes, equal to $66^{\prime} 6$ ampere hours-that is, it would yield a current at the rate of 66 ampères for one hour. The electro-motive force of each cell is $2 \cdot 1$ volts, the internal resistance being . $01 \mathrm{ohm}$. Three cells, as employed in the above case, yield, when joined together in a series, a current at the rate of 66 amperes with an electro-motive force of 6 volts for one hour.

Note.-Since reading the above paper, I have to record the death of the patient, which occurred quietly on March 16th. He gradually sank from exhaustion, with evidences in the floor of the mouth of a return of the disease. Up to the last moment of his life he was quite free from pain, and complained of nothing but increasing weakness. His condition precluded any hope of his being benefited by a second operation; but his peaceful and painless death when contrasted with the usual terminations of cases of cancer of the tongue, shows that even when the disease cannot be totally eradicated, much can be gained in the way of comfort for the sufferer by operative measures.

\section{REMARKS ON PERINEAL LACERATIONS.}

By GEORGE ELDER, M.D.,

SURGEON TO THE HOSPITAL FOR WOMEN, NOTTINGHAM,

IN treating of lacerations of the perineal body, I purposely exclude vaginal orificial tears, which, according to Dr. Matthews Duncan (vide Papers on the Female Perineum), are inevitable in the primiparous female, and also such rare accidents as central rupture; but confine myself to the more familiar, but not less important, lesions of contiguity ranging from mere slitting of the fourchette to rupture into the bowel. That these cases have at least not hitherto received that attention which they demand is shown by the large number of women who daily seek relief at our hospitals from sufferings due to this potent factor of uterine mischief. The custom hallowed by age, of tying the knees together when this accident occurs, using disinfectant vaginal irrigations, and hoping for the best, is, I grant, in many cases followed by no immediate illeffects; but when now and again, as inevitably they must, the torn surfaces become sodden and ashy grey surfaced, the precursors of puerperal septicœmia, then probably it flashes across our minds that had modern surgical ideas been imported into the case, it might have had a different ending. There are certain patients in whom from a weakened condition of the tissues, due either to a cachexia-sucb, for example, as syphilis or local inflammatory changes-lacera. tions are unavoidable. Occupying a chief position amongst the causes is the unskilful use of the forceps. Wielded by strong hands, regarding not in what direction traction is being made, they are an instrument powerfal for evil. Conversely, their intelligent use in correcting a malposition, diverting misdirected force, or supplementing feeble propulsive efforts, gives them a place amongst the most valued resources of our art. The element of time is a very important one in ensuring a successful termination to the second stage of labour. In rapid labours there is neither the gradual moulding of the presenting part so necessary, nor is there that due accommodation of the maternal passages so essential to their integrity. As before incidentally mentioned, long-continued pressure upon the maternal tissues, by initiating necrotic changes and subsequent loss of substance, often brings about this accident. So also do small and deformed pelves, malpresentations, cicatricial contractions, and rigidity of the vulvar outlet. When alluding to the injury likely to follow rapid labours, I should have mentioned in this connexion the harmful effect of giving, as is frequently done in a routine fashion, ergot. It is impossible to gauge or control its power upon the uterine muscular fibres, and it cannot be doubted that in many cases it has been followed by the consequences we are considering.

The causes above enumerated find their strongest expression in primipare. The influence which this accident has upon the health of the lying-in woman naturally is divided by time into the immediate and remote, and of the former puerperal septicæmia occupies the premier position. The richness with which the peri-vaginal tissue is endowed with lymphatics and veins offers, once a breach of tissue is accomplished, easy access for the imbibition into the systemic circulation of septic materials. There are few who now cling to the specificity of puerperal fever, but rather look upon it as a blood dyscrasia, having for its exciting cause an autogenetic and heterogenetic source. And whether looked at by the light of modern uterine pathology or clinical experience, it must be confessed that in most instances a probably unnoticed baring and laceration of the absorbent vessels has been the fons et origo mali. The vitiated secretions from torn and bruised surfaces, and under certain conditions even the lochial discharges, doubtless exercise a toxic influence upon the parturient woman, and it is to this view of the majority of examples of puerperal fever the medical opinion of the present day is tending, and upon which must follow practice fraught with nothing but benefit to the community. The acceptance of the principle by the profession at large, that every tear of the maternal passages should be treated according to modern surgical procedure, will do very much towards reducing childbed mortality. Among recent writers on the subject there is none who from the commanding position which be occupies, can speak with greater anthority than Dr. Thomas, who, in an address before the New York Academy of Medicine on Dec. $6 \mathrm{th}, 1883$, with convincing eloquence demolished the specific theory, and showed how in most cases the inception of puerperal septicemia was traceable to the mal-influence of lesions of the genital tract.

Leaving this, which, after all, is debateable ground, it must be conceded by everyone familiar with the subject that the presence of perineal lacerations interferes with uterine and vaginal involution, laying thereby the seeds of future pelvic trouble. Of the remote effects of these rents there is some divergence of opinion, hinging as it does in great measure on the part which the perineum plays in the support of the uterus. Doubtless everyone sees now and again cases even of complete procidentia with perfect perineal bodies, but these are nothing to the large number applying for relief with varying degrees of uterine prolapse and histories and evidences of perineal lacerations. The rupture to any extent of the muscular conjunction which takes place at the perineum must, by interfering with the solidarity of the sacral 
segment of the pelvic floor, allow the anterior vaginal wall to bag, and following it the uterine body and appendages. It is upon the woman whose daily labour is hard and exacting that this condition presses the most heavily. Prolapse or procidentia means to her crippled usefulness, and in many instances total inability to follow the occupation which has brought her bread. When the anal sphincteric fibres have been torn incompletely, incontinence of flatus and liquid freces are produced, with liability to frequently recurring attacks of diarrhcea. With complete rupture there supervenes a condition so intolerable that its sufferers are ready to loathe even their very existence. The treatment of these cases resolves itself into the preventive and the curative. The first and most important presupposes an intelligent appreciation of the mechanism of parturition, and carrying its lessons into practice. The correction of malpresentation and of misdirection of the propulsive force, preventing precipitate labour by direct backward pressure upon the presenting part, the judicious use of chloroform, injunctions to cease voluntary efforts, avoidance of ergot and supplementing in other cases the muscular contractions by the careful use of the forceps, briefly summarise the main indications. The Dublin plan of taking off the blades of the forceps when the vulvar outlet is reached is worthy of adoption. When laceration is impending and unavoidable, its extent may be limited by notching either side of the raphe. The accident having happened, unless extremely trifling and tegumentary, its immediate repair is demanded and towards the general adoption of this practice when needed no parturient woman should be left without a visual examination of the vulvar outlet being made. Stunned by the passage of the child, the parts are less sensitive than later, and the bringing together of the torn surfaces is a matter not difficult of accomplishment. The relaxed state of the parts also favours apposition. Even as late as a week after confinement I have obtained perfect union in a deep laceration. When the time for the primary operation has passed, it is well to wait till after the cessation of lactation; the procedure is then more or less troublesome according to the extent of tissue involved and the general health of the patient. When the laceration is incomplete vivification of the cicatrised surfaces, accurate apposition, and careful after-treatment make this operation one of the most successful in surgery ; but if the recto-vaginal septum is more or less destroyed, its renewal requires considerable skill. In two recent cases of extensive rents of the septum I have obtained excellent results by making two vaginal and two rectal flaps (as suggested, I believe, by Mr. Hulke), getting between them a good perineal body. For the flaps carbolised silk is better than catgut, unless chromicised catgut is used, because of its speedy solution; and for the deep perineal sutures silver wire is preferable, simply twisted or fastened by perforated shot. Vaginal injections are usually practised after the operation; but it seems to me better to pack the vagina with an absorbent aseptic material like iodoform cotton-wool, thus getting all the advantage to be derived from rest to the parts-pressure and dryness. This need not often be changed. A self-retaining catheter, either a Skene-Goodman or a Holt with attached tubing, keeps the patient free from urinous dribbling. The accumulation of flatus may interfere with healthy union, and to obviate this the occasional use of a rectal tube is indicated. The period at which the bowels should be relieved is a moot point, and an important one. If too soon, it must, I think, interfere with the reparative process, unless the utmost care is taken ; and if too long delayed, the passage of scybalæe may rupture the young tissues. When the latter are suspected, means should be taken to break them up; and in addition to a saline purgative an enema of oil should be administered.

Nottingham.

Convalescent ATD. - On the 24th inst., a meeting was held at the Mansion House in support of the plan of convalescent aid adopted by the Charity Organisation Society. Lord Carnarvon, who occupied the chair, stated that the scheme had been in existence now for over twelve months, and up to the present had worked well. A resolution to the effect that convalescent aid has a most important bearing upon the health of the people, was carried unanimously. As a proof of the importance of such work, we may mention that the Me r spolitan Convalescent Institution has since its forma. tion relieved nearly 100,000 persons.
A CASE OF

SYPHILITIC PARAPLEGIA, WITH REMARKS.

BY WILLIAM S. PORTER, M.D.,

PHYSICIAN TO THE SHEFFIELD PUBLIC HOSPITAL AND DISPENSARY.

W. B-C, aged twenty-eight, was admitted into the Sheffield Pablic Hospital and Dispensary, under my care, on the 31st of January last, suffering from paraplegia. He had noticed some weakness in his legs since shortly after Christmas, but had experienced no difficulty in walking until about a week before he was admitted. He had had some pain about the upper lumbar vertebræ, and at first slight twitchings in both lower extremities, beginning in the right. The usual inquiries into his previous history elicited the following facts: He had had good health until he was between twelve and fourteen years of age, when he had a sore on his tongue, a hard swelling beneath the jaw, and a sore throat and mouth. He could not remember having any rash or spots on his skin, but said hat his hair came off in considerable quantity soon after the appearance of these symptoms. Neither he nor his father could give a satisfac. tory account of the order in which they occurred. The sore on the tongue took three or four months to heal. Later he had a discharge from the nostrils, and the bridge of his nose sank in. He said that he was again under medical treatment for an affection of both eyes, when he was about sixteen or eighteen years of age. In 1876 be was a patient in the hospital with paraplegia involving the sphincters, but recovered almost completely in the course of a year. He then had fairly good health up to the commencement of his present illness. Inquiries into his family history elicited nothing beyond the fact that of ten brothers and sisters only two were living; of the other eight several were stillborn, and several fell victims to an epidemic of small-pox. His father was living and well, aged seventy, and his mother died of "dropsy" at the age of forty-seven. 'I'he patient had been married seven years, and his wife had had one miscarriage, and one child living and well. $\mathrm{He}$ was fairly well-nourished, but had a very sallow, earthr complexion, and a very flattened, syphilitic-looking nose. On the dorsum of his tongue, to the right of the median line, was a depressed and puckered cicatrix. The soft palate was partially destroyed by old ulceration, and adherent on the right side to the back of the pharynx. There were no scars about the body, face, or limbs, no swelling or nodes, no scar on the penis, and no history of venereal disease could be obtained. He complained on admission of slight pain in the back, referred to the upper lumbar vertebræ, and some tenderness on percussion over the spinous processes in the same situation. He experienced a feeling of some stiffness, but no pain in bending or rotating the spine. In the horizontal position with great muscular effort, be could just raise his heel half an inch from the bed, but could not retain it in that position. Both lower extremities were affected equally. There was no wasting and no rigidity or contraction in the muscles of the paralysed limbs, their electro-contractility to faradaism being slightly increased. Cutaneous sensibility was normal below the knee, but lost over the outer surface of both thighs, corresponding to the distribution of the external cutaneous nerve. Over the abdomen, back, buttocks, and posterior and inner surface of both thighs sensation was normal. The superficial reflexes were increased, except the cremasteric reflex, which was absent on both sides. Patellar-tendon reflex was exaggerated in both limbs, and ankle clonus was very marked in the right leg, only slightly noticeable in the left. There was a small patch of interstitial opacity on the left cornea, and with the ophthalmoscope slight cloudiness of the right cornea was detected. The discs were healthy, but there was a slight crescent-shaped patch of choroidal atrophy to the outer side of the right disc. The pupils were normal, and there were no traces of former iritis. The heart, lunge, urine, temperature, and pulse afforded no indication of any abnol. mality. The tongue was clean and moist, and appetite good, but the patient complained of abdominal pain, and had very troublesome diarrhoea. The liver and spleen were not enlarged. Under iodide of potassium, increased from ten. up to twenty-grain doses, and mercurial inunction over the spine, the patient made rapid progress towards recovery day by day. On the sixteenth day after admission he was able to walk a little without as:istance, and soon after left the hos- 